\title{
The effect of sun exposure on 25-hydroxyvitamin D concentrations in young healthy subjects living in the city of São Paulo, Brazil
}

S.S. Maeda, I.S. Kunii, L. Hayashi and M. Lazaretti-Castro
Disciplina de Endocrinologia e Metabologia, Escola Paulista de Medicina, Universidade Federal de São Paulo, São Paulo, SP, Brasil

\begin{abstract}
Correspondence
S.S. Maeda

Rua Conselheiro Furtado, 847/93

01511-001 São Paulo, SP

Brasil

Fax: +55-11-5579-6636

E-mail: mlazaretti@endocrino.epm.br

and ssetsuo@terra.com.br

Research supported by FAPESP

(No. 03/13194-6).

$\ldots \ldots \ldots \ldots \ldots \ldots \ldots$
\end{abstract}

Received July 16, 2006 Accepted June 25, 2007 $\ldots \ldots \ldots \ldots \ldots \ldots \ldots$

\section{Abstract}

The range of 25-hydroxyvitamin D (25OHD) concentration was determined in a young healthy population based on bone metabolism parameters and environmental and behavioral aspects. We studied 121 healthy young volunteers (49 men, 72 women) living in São Paulo ( $23^{\circ} 34^{\prime}$ south latitude) belonging to three occupational categories: indoor workers $(\mathrm{N}=28)$, medical school students $(\mathrm{N}=44)$, and resident physicians $(\mathrm{N}=49)$. Fasting morning blood samples were collected once from each volunteer from August 2002 to February 2004, and 25OHD, total calcium, albumin, alkaline phosphatase, phosphorus, creatinine, intact parathyroid hormone, osteocalcin, and type I collagen carboxyterminal telopeptide were measured. Data are reported as means \pm SD. Mean subject age was $24.7 \pm 2.68$ years and mean 25OHD level for the entire group was $78.7 \pm 33.1 \mathrm{nM}$. 25OHD levels were lower $(\mathrm{P}<0.05)$ among resident physicians $(67.1 \pm 27.0$ $\mathrm{nM})$ than among students $(81.5 \pm 35.8 \mathrm{nM})$ and workers $(94.0 \pm 32.6$ $\mathrm{nM}$ ), with the last two categories displaying no difference. Parathyroid hormone was higher $(\mathrm{P}<0.05)$ and osteocalcin was lower $(\mathrm{P}<$ 0.05 ) among resident physicians compared to non-physicians. Solar exposure and frequency of beach outings showed a positive association with 25OHD $(\mathrm{P}<0.001)$, and summer samples presented higher results than winter ones $(97.8 \pm 33.5$ and $62.9 \pm 23.5 \mathrm{nM}$, respectively). To define normal levels, parameters such as occupational activity, seasonality and habits related to solar exposure should be taken into account. Based on these data, we considered concentrations above $74.5 \mathrm{nM}$ to be desired optimal 25OHD levels, which were obtained during the summer for $75 \%$ of the non-physicians.

\section{Introduction}

Vitamin D is undoubtedly important for bones. Its deficiency is associated with osteomalacia and/or rickets, causing deformities and fractures (1-3). Nevertheless, values
Key words

- 25-Hydroxyvitamin D

- Parathyroid hormone

- Occupational aspects

- Seasonal influence

- 25OHD and solar exposure 
of the vitamin is cutaneous synthesis catalyzed by the sun's rays. Its principal circulating metabolite is 25-hydroxyvitamin D (25OHD), whose serum concentrations are used to monitor vitamin D nutritional status.

It is believed that the first human beings originated in Africa thousands of years ago. When they began to migrate north, their skin was dark, and the whitening of their skin was an adaptation which prevented vitamin D deficiency and allowed them to survive despite the lower amount of ultraviolet rays found in their new habitats. Migratory movements occurring during recent centuries, however, have not led to any adaptations to new climate conditions due to the short period of time over which they have occurred (4). Furthermore, cultural modifications have altered worldwide social habits, dictating longer periods indoors and the use of heavier clothes, in addition to greatly increasing life expectancy. These modifications have resulted in our conceptual loss of the ideal value of $25 \mathrm{OHD}$, and the scientific community is broadly engaged in discussion about the normal circulating concentration of this metabolite.

Recent studies determining mean values of serum 25OHD in different regions have concluded that, contrary to expectations, subjects residing in southern Europe present lower values than their northern counterparts, probably due to supplementation via medication and dietary enrichment (5). Vitamin $\mathrm{D}$ deficiency has been neglected in the more sunny regions. In a study carried out by our group in the city of São Paulo, Brazil ( $23^{\circ} 34^{\prime}$ S latitude), we observed very low mean serum 25OHD concentrations (29.1 $\mathrm{nM})$ in a free-living elderly people (79.1 years old) after winter (6). These findings encouraged us to determine 25OHD levels in the young population living in São Paulo, that is, one comprised of young people at their peak of bone mass, and this became the focus of the present study. Our aim was to determine the distribution of 25OHD levels in a young healthy population and to investigate their relationship to sun exposure.

\section{Subjects and Methods}

\section{Subjects}

Normal individuals of both sexes aged 17-35 years were recruited from 3 different locations within the city of São Paulo: two medical schools and a mechanical factory. Blood samples were collected once at two different times: winter (samples collected between August and September), and summer (January and February). Individuals were required to be in good health (i.e., not displaying any known disease), and were excluded if taking medication or vitamin supplements, with the exception of contraceptive pills. Other exclusion criteria were pregnancy and the identification of any relevant alteration in the laboratory screening.

A total of 127 young individuals living in São Paulo agreed to participate in the study and met inclusion criteria. Six were excluded due to relevant laboratory alterations. The final group comprised 121 subjects (49 men and 72 women) aged 17-33 years, mean age $24.7 \pm 2.7$ years; 89 of them of European descent (73.6\%), 26 of Asian descent (21.5\%), and 6 of African descent (4.9\%). At the end of the inclusion, participants were categorized into three groups according to their occupational activities: 49 were medical residents $(39.7 \%$, mean age $26.4 \pm 0.25$ years old), 44 were medical students (36.4\%, mean age $23.2 \pm 0.14$ years old), and 28 were indoor workers $(23.1 \%$, mean age $24.9 \pm$ 0.80 years old). Groups were divided as such due to the demanding schedules of medical residents, whose activity consists of $60 \mathrm{~h} /$ week with at least 1 night duty. Plant and office workers work $40 \mathrm{~h} /$ week, predominantly indoors. Men had a higher mean weight $(72.4 \pm 9.4 \mathrm{~kg})$, height $(1.74 \pm 0.06$ m) and body mass index $\left(23.6 \pm 2.8 \mathrm{~kg} / \mathrm{m}^{2}\right)$ compared to women $(58.3 \pm 10.1 \mathrm{~kg} ; 1.63 \pm$ 
$0.06 \mathrm{~m}$, and $21.8 \pm 3.2 \mathrm{~kg} / \mathrm{m}^{2}$, respectively).

\section{Methods}

Calcium ingestion was estimated on the basis of the results of a summarized questionnaire concerning dairy milk product consumption. Participants were categorized as low ( $<500 \mathrm{mg} /$ day), medium (between 500 and $1000 \mathrm{mg} /$ day), or high (>1000 mg/day) calcium consumers depending on their response to the questionnaire. Food calcium content was calculated based on the Food Composition Table of the U.S. Department of Agriculture/Agricultural Research Service 2001 (www.nal.usda.gov/fric/foodcomp/).

The exposure of these individuals to sunlight was evaluated according to their selfreported exposure habits, number of beach outings, and use of sunscreen. Sunlight exposure was considered to be low when the subject sunbathed less than three times a week for a period shorter than $15 \mathrm{~min} /$ day, exposing only the face and arms. Exposure was considered to be high when the subject reported sunbathing at least five times a week for more than $30 \mathrm{~min}$ at a time, exposing the face, arms, and thorax. A third group of individuals reported intermediate sunlight exposure between the aforementioned criteria. Subjects were also classified into three groups according to number of beach outings: low frequency ( 0 to one outing per year), intermediate frequency (two to four outings per year), and high frequency (more than four outings per year).

The study protocol was approved by the Ethics Committee of UNIFESP, and all participants gave written informed consent.

An 8-h fasting morning blood sample was collected once from each volunteer over the course of the year for the determination of $25 \mathrm{OHD}$, total calcium, albumin, total alkaline phosphatase (AP), phosphorus, creatinine, thyroid-stimulating hormone, intact parathyroid hormone (PTH), osteocalcin (OC), and carboxyterminal telopeptide of type I collagen (CTX). All serum samples were collected into refrigerated tubes, processed in refrigerated centrifuges, and frozen at $-20^{\circ} \mathrm{C}$ until measured.

Calcium, phosphorus, creatinine, and albumin were measured by automated colorimetric method (BM/Hitachi 917, Manheim, Germany). Commercial immunoassays (chemiluminescence-Elecsys analyzers-Roche, Indianapolis, IN, USA) were used to quantify OC and CTX. AP was measured by a kinetic enzyme method, thyroid-stimulating hormone by an in-house immunofluorimetric method, and PTH by an in-house electrochemiluminescence immunoassay (7). Reference values for these methods are presented in Table 1.

25OHD concentrations were determined by an immunoradiometric assay (Nichols Institute Diagnostics, San Juan Capristrano, CA, USA). Intra-assay coefficient of variation was $4.8 \%$, and inter-assay coefficient of variation was $16.0 \%$ for the lowest values (mean: $35.5 \mathrm{nM}$ ) and $3.0 \%$ for the highest control (mean: $154.0 \mathrm{nM}$ ).

\section{Statistical analysis}

The Kolmogorov-Smirnov test was used to evaluate the normality of quantitative variables. Mann-Whitney test was used to test the difference between two independent groups. The correlation between $25 \mathrm{OHD}$ and other quantitative variables was evaluated by the Pearson linear correlation. The Kruskal Wallis test was used for the comparison of quantitative variables not presenting normal distribution within more than two groups, and when these were significant, the multiple comparison test was used. The chisquare $\left(\chi^{2}\right)$ test was used to evaluate the independence between the variables "beach outings" and "sunlight exposure". Fisher's exact test was used to evaluate homogeneity among races in relation to occupational categories. A generalized linear model (Gamma distribution) was used to assess the influ- 
Table 1. Comparison of serum 25OHD, CTX, OC, and PTH concentrations in physicians and non-physicians.

\begin{tabular}{llccc}
\hline $\begin{array}{l}\text { Parameter } \\
\text { (reference values) }\end{array}$ & $\begin{array}{l}\text { Occupational } \\
\text { activity }\end{array}$ & $\begin{array}{c}\text { 25OHD } \\
\text { (mean } \pm \mathrm{SD})\end{array}$ & Minimum & Maximum \\
\hline 25OHD (nM) & Physician & $67.1 \pm 27.0^{*}$ & 24.0 & 135.0 \\
& Non-physician & $86.3 \pm 34.9$ & 24.0 & 214.0 \\
CTX (0.01-5.94 ng/mL) & Physician & $0.350 \pm 0.170$ & 0.067 & 0.990 \\
& Non-physician & $0.560 \pm 0.300$ & 0.119 & 1.670 \\
OC (11-43 ng/mL) & Physician & $23.6 \pm 7.6^{*}$ & 10.7 & 45.1 \\
& Non-physician & $30.4 \pm 10.3$ & 8.5 & 55.1 \\
PTH (10-70 pg/mL) & Physician & $29.1 \pm 12.7^{*}$ & 10.4 & 64.0 \\
& Non-physician & $26.2 \pm 15.6$ & 5.0 & 74.0 \\
\hline
\end{tabular}

$25 \mathrm{OHD}=25$-hydroxyvitamin $\mathrm{D} ; \mathrm{CTX}=$ carboxyterminal telopeptide of type I collagen; $\mathrm{OC}=$ osteocalcin; PTH = intact parathyroid hormone.

${ }^{*} \mathrm{P}<0.05$ compared to non-physicians (Mann-Whitney test).

Table 2. Distribution of serum 25-hydroxyvitamin D (25OHD) concentrations according to percentiles, considering the group as a whole, occupational activity and the sampling period.

\begin{tabular}{|c|c|c|c|c|c|c|c|}
\hline Parameter & Category & $5 \%$ & $25 \%$ & $50 \%$ & $75 \%$ & $95 \%$ & $\mathrm{~N}$ \\
\hline Whole group & & 33.0 & 55.0 & 72.0 & 100.0 & 134.0 & 121 \\
\hline \multirow[t]{2}{*}{ Occupational activity } & Physician & 32.0 & 48.0 & 61.0 & 80.0 & 128.0 & 49 \\
\hline & Non-physician & 33.0 & 59.0 & 85.0 & 111.0 & 142.0 & 72 \\
\hline Season & Winter & 26.4 & 47.0 & 68.0 & 90.0 & 116.4 & 35 \\
\hline (non-physician) & Summer & 46.6 & 74.5 & 103.0 & 124.0 & 164.5 & 37 \\
\hline
\end{tabular}

Serum $250 H D$ is reported in $\mathrm{nM}$.

Figure 1. Concentrations of 25hydroxyvitamin $\mathrm{D}(25 \mathrm{OHD})$ according to occupational activity and season when the sampling was carried out. Significant differences were found only between winter samplings, indicated by the boxes with horizontal lines. ${ }^{*} P<0.05$ (Kruskal Wallis test). In the summer there were no differences between the three groups. The first small circle corresponds to a medical resident who had $99 \mathrm{nM}$ in the winter and the second circle, a medical student who had $214 \mathrm{nM}$ in the summer.

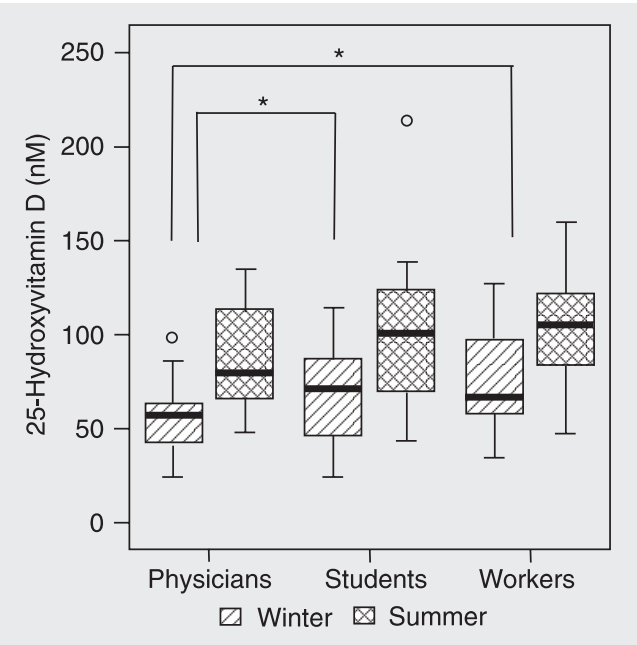

ence of different factors on 25OHD. Data are reported as percentiles or means $\pm \mathrm{SD}$. Differences were considered significant if $\mathrm{P}$ $<0.05$.

\section{Results}

The three groups (medical residents, medical students and workers) did not differ regarding gender, calcium intake, or use of sunscreen. There was a predominance of medical residents in the winter group $\left(\chi^{2}, \mathrm{P}\right.$ $=0.049)$. As such, this group tended to be older $(\mathrm{P}<0.001)$ and had a lower degree of sun exposure compared to the other groups $(\mathrm{P}<0.001)$.

There was no difference in weight, height or body mass index among the groups with different occupational activities.

Low dairy calcium intake was detected in $47.1 \%$ of the young individuals, and only $9.1 \%$ of them had a high intake. Almost half the subjects reported a low frequency of beach outings (40.5\%), whereas $21.5 \%$ reported a high frequency. Additionally, 28.9\% of the participants reported low sunlight exposure and $19.0 \%$ reported high exposure.

Laboratory data for the group as a whole and according to occupational activities are shown in Table 1. Mean serum 25OHD concentration was $78.7 \pm 33.1 \mathrm{nM}$ for the group as a whole, with no statistical gender-related difference. Total calcium correlated negatively with $25 \mathrm{OHD}$ levels $(\mathrm{r}=-0.21, \mathrm{P}=$ 0.023 ), but there was no correlation between PTH, AP, phosphorus, CTX, or OC and 25OHD in the group as a whole. Similarly, there was no correlation between calcium intake and PTH levels $(\mathrm{P}=0.516)$. As expected, men had higher values than women for OC $(31.7 \pm 10.3$ and $24.9 \pm 8.7 \mathrm{ng} / \mathrm{mL}$, respectively) and CTX $(0.630 \pm 0.32$ and $0.370 \pm 0.18 \mathrm{ng} / \mathrm{mL}$, respectively).

A significant difference in $25 \mathrm{OHD}$ values $(\mathrm{P}=0.002)$ was observed regarding occupational activities (Table 2). Resident physicians presented lower means $(67.1 \pm$ 
$27.0 \mathrm{nM}$ ) than both medical school students $(81.5 \pm 35.8 \mathrm{nM})$ and indoor workers $(94.0 \pm$ $32.6 \mathrm{nM}$ ), with no significant difference between the latter two groups. PTH, OC, and CTX levels were similar for workers and students, who were considered here as one group (non-physicians). Additionally, higher PTH values $(\mathrm{P}<0.001)$ and lower OC values $(\mathrm{P}<0.001)$ were observed in physicians when compared to non-physicians, as shown in Table 1.

The mean 25OHD concentration was higher in blood samples collected during the summer $(97.8 \pm 33.5 \mathrm{nM})$ than in those collected during the winter $(62.9 \pm 23.5$ $\mathrm{nM})$, whereas PTH concentrations did not differ according to season $(26.3 \pm 14.6 \mathrm{pg} /$ $\mathrm{mL}$ in the winter and $26.1 \pm 16.7 \mathrm{pg} / \mathrm{mL}$ in the summer, $\mathrm{P}=0.892$ ). Figure 1 shows the differences observed according to the period when the sample was collected and according to occupational category. It was observed that physicians presented significantly lower $25 \mathrm{OHD}$ values than other participants only in the winter $(\mathrm{P}=0.027)$.

There was an association between $25 \mathrm{OHD}$ concentrations and beach outing frequency $(\mathrm{P}<0.001)$. The multiple comparison test showed that participants who reported low beach outing frequency presented lower serum 25OHD levels than participants reporting an intermediate $(\mathrm{P}=0.002)$ or high frequency $(\mathrm{P}=0.0001)$, with the latter two categories showing no statistically significant differences $(\mathrm{P}=0.1942)$. These differences were maintained when the data were analyzed separately according to season $(\mathrm{P}$ $=0.004$ in the winter and $\mathrm{P}=0.04$ in the summer).

Similarly, there was an association between 25OHD levels and sunlight exposure $(\mathrm{P}<0.001)$. The multiple comparison test showed that subjects reporting low sunlight exposure presented lower serum 25OHD levels than those reporting intermediate $(\mathrm{P}=$ $0.0005)$ or high exposure $(\mathrm{P}<0.0001)$, with the latter two categories again displaying no statistical difference $(\mathrm{P}=0.0608)$. These differences were maintained in both winter $(\mathrm{P}=0.024)$ and summer $(\mathrm{P}=0.002)$.

No significant differences in serum 25OHD levels were observed between women taking contraceptive pills or not $(\mathrm{P}=$ 0.061). Similarly, there were no differences in serum 25OHD regarding ethnic group, use of sunscreen, or calcium intake.

\section{Discussion}

The discussion about what should be normal serum 25OHD levels continues $(8,9)$. Young healthy individuals of three different occupational categories were included in the present investigation: individuals working day shifts for $40 \mathrm{~h} /$ week, predominantly indoors (offices and industries), students from two different medical schools, and resident physicians from the same two medical schools, whose work activity consists of 60 $\mathrm{h} /$ week, chiefly night shifts. These normal individuals displayed a broad range of serum 25OHD concentrations, from 24 to 214 nM. While resident physicians presented lower values in comparison to students and workers, this apparently was corrected when solar exposure was more intense, i.e., during the summer, when the difference disappeared.

Our group as a whole presented mean serum 25OHD of 78.7.1 $\pm 33.1 \mathrm{nM}$, which is close to the value presented by others from northern hemisphere countries (10-12).

There was a significant correlation among parameters related to solar exposure and serum 25OHD. These data agree with several other studies and confirm the fundamental importance of the sun's rays in the formation of vitamin D stores (13-17). Our results showed that an intermediate exposure to sunlight (three times a week for 15 min per day exposing face and arms) was enough to produce a significant increase on 25OHD levels. The high exposure group was not different from the intermediate ex- 
posure group.

Most investigations aim to study serum $25 \mathrm{OHD}$ levels in the elderly population, in which the inverse correlation between this hormone and PTH is more evident $(6,18$ 21). As a result, PTH has been considered to be one of the markers for sufficient and insufficient vitamin D. However, the correlations obtained between PTH and 25OHD usually are of small magnitude and show wide individual variability, even in aged people (18). In young populations, this correlation is not always observed (22), as was the case in the present study. The cut-off value for 25OHD below which PTH secretion starts to increase is apparently lower for younger than for older people. Docio et al. (23) suggested that the threshold value for vitamin D deficiency in children (aged 7-10 years) is about 30-50 nM, above which enhanced PTH levels are observed, while in adults, a stable plateau for PTH was obtained when serum 250HD levels were higher than $78 \mathrm{nM}(24,25)$. Despite the lack of a correlation between PTH and 25OHD in our study, physicians, who had lower 25OHD levels, presented significantly higher PTH levels compared to non-physicians. Similarly, OC levels, a bone formation marker, were lower in the physicians' group. This indicates that their low levels had undesired consequences on mineral metabolism, and cannot be considered normal. Taking this into account, we concluded that this population had to be excluded for the definition of a normal range (Table 2).

For the remaining subjects in the group, we obtained a mean $250 \mathrm{OHD}$ value of $86.3 \pm$ $34.9 \mathrm{nM}$. If we consider only the results found in summer (Table 2), $75 \%$ of the individuals presented values higher than 74.5 nM (median: $103.0 \mathrm{nM}$ ). We believe that these results can be applied to the young individuals. Based on our results, oral vitamin D supplementation could even be indicated to healthy young individuals who do not have the possibility of adequate sunlight exposure.

\section{References}

1. Parfitt AM, Gallagher JC, Heaney RP, Johnston CC, Neer R, Whedon GD. Vitamin D and bone health in the elderly. Am J Clin Nutr 1982; 36: 1014-1031.

2. Riggs L, Melton LJ III. Medical progress: Involutional osteoporosis. N Engl J Med 1986; 314: 1676-1686.

3. Utiger RD. The need for more vitamin D. N Engl J Med 1998; 338: 828-829.

4. Jablonski NG, Chaplin G. The evolution of human skin coloration. $J$ Hum Evol 2000; 39: 57-106.

5. Lips P, Duong T, Oleksik A, Black D, Cummings S, Cox D, et al. A global study of vitamin D status and parathyroid function in postmenopausal women with osteoporosis: baseline data from the multiple outcomes of raloxifene evaluation clinical trial. J Clin Endocrinol Metab 2001; 86: 1212-1221.

6. Saraiva GL, Cendoroglo MS, Ramos LR, Araujo LM, Vieira JG, Kunii I, et al. Influence of ultraviolet radiation on the production of 25 hydroxyvitamin $D$ in the elderly population in the city of São Paulo (23 degrees 34'S), Brazil. Osteoporos Int 2005; 16: 1649-1654.

7. Vieira JGH, Nishida SK, Kasamatsu TS, Amarante EC, Kunii IS. Development and clinical application of an immunofluorometric assay for intact parathyroid hormone. Braz J Med Biol Res 1994; 27:
2379-2382.

8. Dawson-Hughes B, Heaney RP, Holick MF, Lips P, Meunier PJ, Vieth R. Estimates of optimal vitamin D status. Osteoporos Int 2005; 16: 713-716.

9. Holick MF. The parathyroid hormone D-lema. J Clin Endocrinol Metab 2003; 88: 3499-3500.

10. Aksnes L, Rodland O, Aarskog D. Serum levels of vitamin D3 and 25-hydroxyvitamin D3 in elderly and young adults. Bone Miner 1988; 3: 351-357.

11. Tangpricha V, Pearce EN, Chen TC, Holick MF. Vitamin D insufficiency among free-living healthy young adults. Am J Med 2002; 112: 659-662.

12. Romagnoli E, Caravella P, Scarnecchia L, Martinez P, Minisola S. Hypovitaminosis D in an Italian population of healthy subjects and hospitalized patients. Br J Nutr 1999; 81: 133-137.

13. Gannage-Yared MH, Chemali R, Yaacoub N, Halaby G. Hypovitaminosis $D$ in a sunny country: relation to lifestyle and bone markers. J Bone Miner Res 2000; 15: 1856-1862.

14. Matsuoka LY, Ide L, Wortsman J, MacLaughlin JA, Holick MF. Sunscreens suppress cutaneous vitamin D3 synthesis. J Clin Endocrinol Metab 1987; 64: 1165-1168. 
15. Matsuoka LY, Wortsman J, Dannenberg MJ, Hollis BW, Lu Z, Holick MF. Clothing prevents ultraviolet-B radiation-dependent photosynthesis of vitamin D3. J Clin Endocrinol Metab 1992; 75: 1099-1103.

16. Fuleihan GE, Deeb M. Hypovitaminosis D in a sunny country. $N$ Engl J Med 1999; 340: 1840-1841.

17. Sedrani SH, Elidrissy AW, El Arabi KM. Sunlight and vitamin D status in normal Saudi subjects. Am J Clin Nutr 1983; 38: 129-132.

18. Lips $P$. Vitamin $D$ deficiency and secondary hyperparathyroidism in the elderly: consequences for bone loss and fractures and therapeutic implications. Endocr Rev 2001; 22: 477-501.

19. Chapuy MC, Pamphile R, Paris E, Kempf C, Schlichting M, Arnaud $\mathrm{S}$, et al. Combined calcium and vitamin D3 supplementation in elderly women: confirmation of reversal of secondary hyperparathyroidism and hip fracture risk: the Decalyos II study. Osteoporos Int 2002; 13: 257-264.

20. Freaney R, McBrinn Y, McKenna MJ. Secondary hyperparathyroidism in elderly people: combined effect of renal insufficiency and vitamin D deficiency. Am J Clin Nutr 1993; 58: 187-191.
21. Souberbielle JC, Cormier C, Kindermans C, Gao P, Cantor T, Forette $F$, et al. Vitamin D status and redefining serum parathyroid hormone reference range in the elderly. J Clin Endocrinol Metab 2001; 86: 3086-3090.

22. Guillemant J, Cabrol S, Allemandou A, Peres G, Guillemant S. Vitamin D-dependent seasonal variation of $\mathrm{PTH}$ in growing male adolescents. Bone 1995; 17: 513-516.

23. Docio S, Riancho JA, Perez A, Olmos JM, Amado JA, GonzalezMacias J. Seasonal deficiency of vitamin D in children: a potential target for osteoporosis-preventing strategies? J Bone Miner Res 1998; 13: 544-548.

24. Chapuy MC, Preziosi P, Maamer M, Arnaud S, Galan P, Hercberg $S$, et al. Prevalence of vitamin $D$ insufficiency in an adult normal population. Osteoporos Int 1997; 7: 439-443.

25. Oliveri MB, Wittich A, Mautalen C, Chaperon A, Kizlansky A. Peripheral bone mass is not affected by winter vitamin $D$ deficiency in children and young adults from Ushuaia. Calcif Tissue Int 2000; 67: 220-224. 